\title{
The expression of CRM1 is associated with prognosis in human osteosarcoma
}

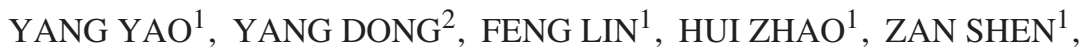 \\ PING CHEN ${ }^{1}$, YUAN-JUE SUN ${ }^{1}$, LI-NA TANG ${ }^{1}$ and SHUI-ER ZHENG ${ }^{1}$ \\ Departments of ${ }^{1}$ Oncology and ${ }^{2}$ Orthopaedics, Affiliated 6th People's Hospital, \\ Shanghai Jiaotong University, Shanghai, P.R. China
}

Received May 20, 2008; Accepted August 5, 2008

DOI: 10.3892/or_00000213

\begin{abstract}
The nuclear export protein chromosomal region maintenance/exportin 1/Xpo1 (CRM1) is involved in the nuclear export of proteins and messenger RNAs and, thus, mediates the subcellular distribution of important molecules. Osteosarcoma is a ubiquitous and highly aggressive malignant bone tumor. The expression of CRM1 protein in human osteosarcoma has not been reported to date. We investigated the expression of CRM1 in 57 human osteosarcoma and 5 normal cartilage tissues. Western blot investigation revealed expression of CRM1 was significantly increased in osteosarcoma compared with normal tissues. High expression of CRM1 was significantly associated with increased serum level of alkaline phosphatase (ALP, $\mathrm{P}=0.001$ ) but did not associate with that of lactate dehydrogenase $(\mathrm{LDH}, \mathrm{P}=0.06)$. In univariate analysis, a significant association between CRM1 expression and tumor size $(\mathrm{P}=0.014)$ as well as histological grade $(\mathrm{P}=0.003)$ was observed, while high $\mathrm{CRM} 1$ expression was not correlated with the other clinicopathological parameters. In Kaplan-Meier survival analysis, high CRM1 expression was a significant prognostic indicator for progression-free survival $(\mathrm{P}=0.016)$ as well as overall survival $(\mathrm{P}=0.008)$. Multivariate analysis demonstrated that expression of CRM1 was an independent prognostic parameter for longer overall survival (95\% CI, 1.27-5.39). Additional prospective studies are required to investigate the prognostic role of high expression of CRM1.
\end{abstract}

\section{Introduction}

Osteosarcoma is the most frequent primary malignant bone tumor. It most often originates in the metaphyses of long bones of adolescents. Due to the high rate of systemic

Correspondence to: Professor Yang Yao, Department of Oncology, and Professor Yang Dong, Department of Orthopaedics, Affiliated 6th People's Hospital, Shanghai Jiaotong University, Shanghai 200223, P.R. China

E-mail: shenzanok@yahoo.com

Key words: chromosomal region maintenance/exportin 1/Xpo1, prognosis, osteosarcoma spread, cure is rare after surgical treatment alone. The inclusion of aggressive polychemotherapy into an interdisciplinary treatment concept has led to dramatic prognostic improvements in young patients with seemingly localized extremity disease, with relapse-free survival rates of $\sim 50-80 \%$ reported by specialized centers or multicentric groups (1-8). However, a substantial subgroup of all osteosarcoma patients lacks prognostic markers that could distinguish patients before therapy and drive treatment choices. Consequently, considerable uncertainty about the true success rate of osteosarcoma treatment in the era of polychemotherapy remains. Some research has been made to evaluate new prognostic markers that could contribute to the choice of treatments. Nevertheless, selecting novel prognostic marker is necessary for further improvement in treatment of osteosarcoma $(9,10)$.

Several oncogenes and tumor suppressor genes are reported to be involved in oncogenesis of OS. Although survival rate increased up to $60-70 \%$ within the last 20 years, the problem of non-response to chemotherapy remains. There are many factors thought to have an influence on prognosis of osteosarcoma. The data from some researchers demonstrate that in osteosarcoma, pretreatment serum alkaline phosphatase (ALP) and lactate dehydrogenase (LDH) levels have a prognostic value and they should be considered when evaluating different therapeutic protocols and in planning new randomized clinical trials. It is known that many patients with osteosarcoma have high serum ALP and LDH levels $(11,12)$. However, the exact role of these factors is still controversial.

The human nuclear export protein chromosomal region maintenance/exportin 1/Xpo1 (CRM1) mediates the nuclear export of proteins and messenger RNAs and, thus, is an important regulator of subcellular distribution of key molecules (13-18). In addition to cell-biologic studies that suggested a fundamental role for CRM1 in the regulation of mitosis, Noske et al reported that the expression of this protein is a prognostic factor in human ovarian cancer (19). However, more data should be obtained from other cancers to further evaluate the prognostic value of CRM1 expression.

In this study we investigated the expression of CRM1 and evaluated its prognostic value in osteosarcoma. The 


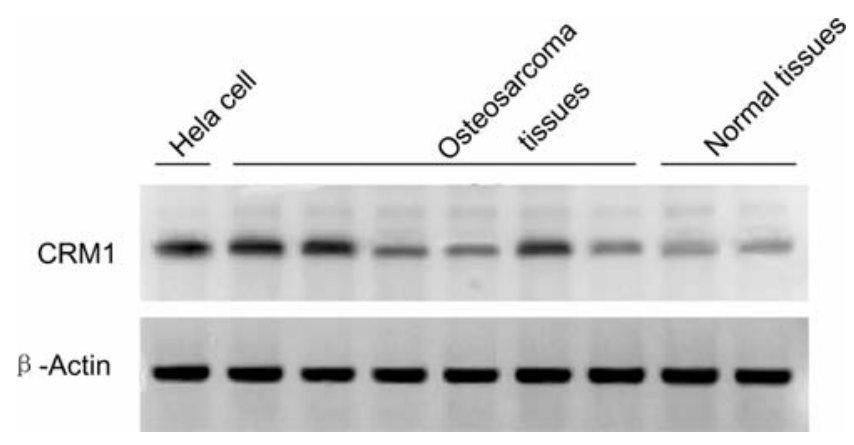

Figure 1. Western blot investigation of CRM1 expression in osteosarcoma and normal tissues. Hela cell lysates is used as positive control. Total protein $(200 \mu \mathrm{g})$ is loaded in each lane. Densitometric ratio (CRM1 expression in tumor or normal sample vs. that in Hela cell) $>0.5$ is considered as high expression, $\leq 0.5$ as low expression.

correlation between CRM1 expression and the clinicopathological parameters of osteosarcoma, including LDH and ALP, was also analyzed.

\section{Materials and methods}

A total of 57 patients were studied. All samples were preoperative samples obtained by biopsy. Clinical and radiological examination revealed the suspicion of osteosarcoma, and then the definitive pathological diagnosis of osteosarcoma was made by the CT-guided puncture or incisional biopsy. There were 57 admitted patients of limb osteosarcoma from January 2002 to December 2006 in Department of Oncology, The Affiliated Sixth People's Hospital, Shanghai Jiaotong University. Pathological grades: G1, well-differentiated; G2, moderately differentiated; G3, poorly differentiated and G4, undifferentiated. The patients were followed up after diagnosis. Physical examination was performed every 3 months in all patients for the first 2 years and then twice/year. Radiographic studies (limb local and chest X-ray), and liver ultrasounds were performed every 12 months; bone scans and computed tomography scans were performed whenever clinically indicated. Blood tests, including electrolyte and liver function profiles and complete blood cell counts, were repeated at every follow-up visit. Pregression-free survival (PFS) was calculated as the period from surgery until the date of the first recurrence.

Treatment. Drugs: methotrexate (MTX), cisplatin (DDP), ifosfamide (IFO) and epirubicin (EPI). Thirty-one cases received 3 courses of neoadjuvant chemotherapy, among them, further 14 cases received one course of chemotherapy with arterial infusion of DDP and EPI. Post-chemotherapeutic surgically treated patients include limb salvage 27 cases, amputation 10 cases. Each post-operative case received 3-8 courses of adjuvant chemotherapy of equal courses. Among 26 cases who did not received neoadjuvant chemotherapy, 13 cases with limb salvage, 13 cases with amputation, post-operative cases with 4-8 course of adjuvant chemotherapy with average courses.
Table I. Patient demographics.

No. of Patients $(\mathrm{N}=57)$

\begin{tabular}{l}
\hline Age (years) \\
Median \\
Range \\
$<12$ \\
$\geq 12$
\end{tabular}

$5-57$

Gender

Male

Female

Local treatment

Surgery, amputation

Surgery, limb-salvage

Surgery, unknown

History of symptoms

Median (days)

72

$<70$ days

$\geq 70$ days

Tumor size (portion of whole bone)

$<$ one third

$\geq$ one third

Metastasis

Absent

44

Detected

Histological type

General

Dilated blood vessels

Cortex

46

5

3

Intra-medullary high differentiated

Others

Grade

G1

G2

G3

6

G4

Primary location

Lower segment of femur

Upper segment of tibia

Upper segment of humerus

Upper end of fibula

Upper segment of femur and lower segment of tibia

Lower segment of humerus and fibula

Duration follow-up (months)

Median

Range

10-52

Relapse

Death 
A

Overall Survival

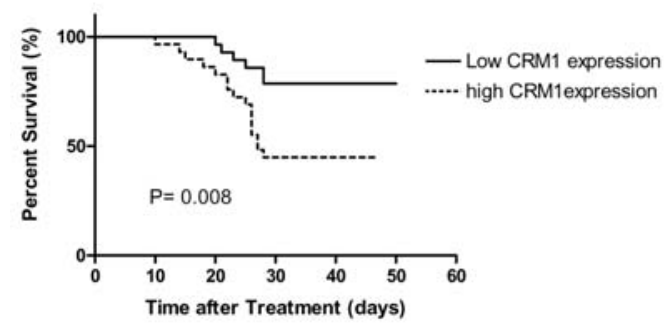

B

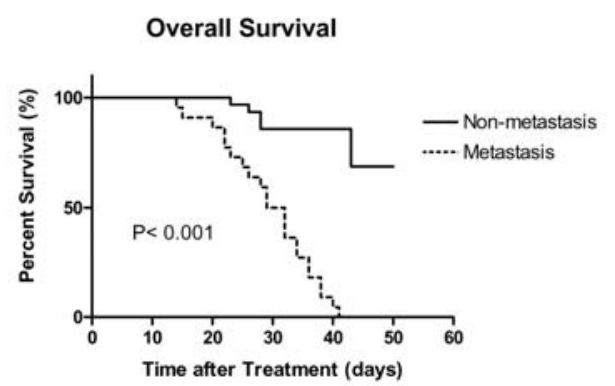

C

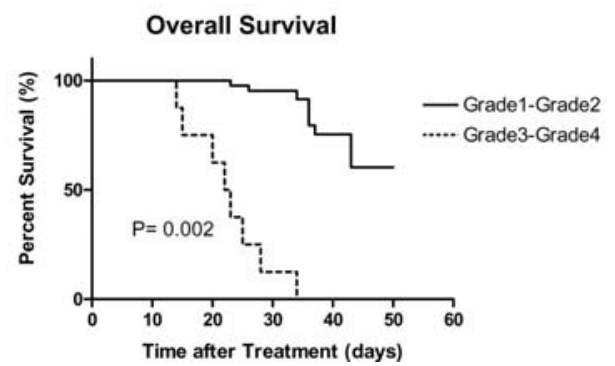

Progression-free Survival

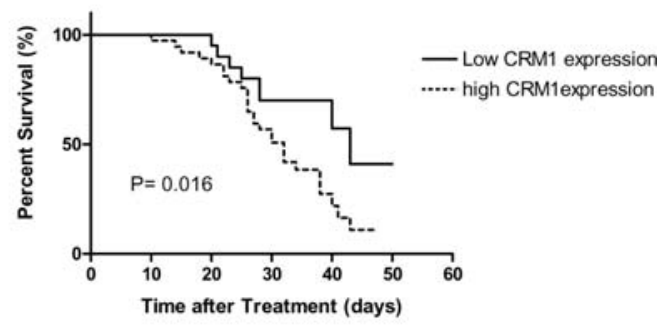

Progression-free Survival

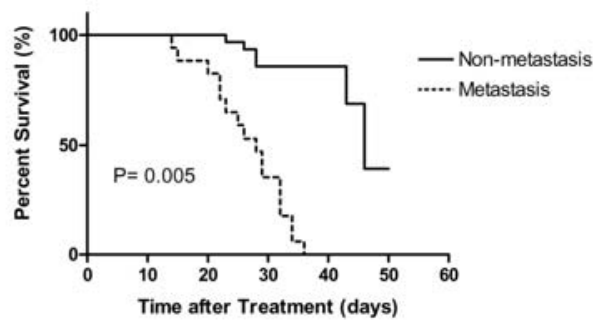

Progression-free Survival

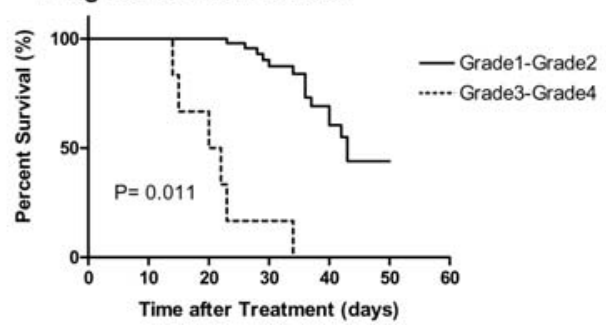

Figure 2. Kaplan-Meier survival analysis of overall survival and progression survival of (A) CRM1 expression, (B) primary metastasis and (C), pathological grades.

Western blotting. For Western blotting, samples were homogenized in a solution of $10 \mathrm{mM}$ HEPES, $10 \mathrm{mM} \mathrm{KCl}$, $1.5 \mathrm{mM} \mathrm{MgCl}_{2}, 0.5 \mathrm{mM}$ DTT, $0.5 \mathrm{mM}$ PMSF, $10 \mu \mathrm{g} / \mathrm{ml}$ aprotinin and $10 \mu \mathrm{g} / \mathrm{ml}$ leupeptin at $\mathrm{pH}$ 7.9. Protein extracts were then subjected to SDS-PAGE and transferred to a polyvinylidene difluoride membrane. The monoclonal antibody against CRM1 was purchased from Santa Cruz Biotechnology (Santa Cruz, CA). The membrane was incubated with primary and secondary antibodies, respectively, for $1 \mathrm{~h}$ at room temperature. Signals were developed by ECL Kit (Amersham Pharmacia Biotech Inc., Buckinghamshire, UK). Hela cells express CRM1 protein and were used as control (20). Blot quantitation was done with a Molecular Dynamics Laser Densitometer (Model PSD) and the Image Quant Version 1 software (21).

Statistical analysis. The statistical significance of the correlation between expression of CRM1 and several clinicopathological parameters was assessed by Fisher's exact test, $\chi^{2}$ test, or $\chi^{2}$ test for trends as indicated. The probability of overall survival as a function of time was determined by the Kaplan-Meier method and the log-rank
Table II. CRM1 expression in ostoesarcomas and normal tissues.

\begin{tabular}{lccc}
\hline & $\begin{array}{c}\text { Osteosarcomas } \\
(\mathrm{n}=57)\end{array}$ & $\begin{array}{c}\text { Normal tissues } \\
(\mathrm{n}=5)\end{array}$ & $\begin{array}{c}\text { P-value } \\
\text { (Fisher's exact } \\
\text { test })\end{array}$ \\
\hline CRM1 expression & & & 0.037 \\
Low & 28 & 5 & \\
High & 29 & 0 & \\
\hline
\end{tabular}

test. Multivariate survival analysis was performed using the Cox regression model. $\mathrm{P}<0.05$ were considered as significant. For the statistical evaluation, the SPSS software version 12.0 was used (SPSS, Inc., Chicago, IL).

\section{Results}

Clinicopathological characteristics of patients with osteosarcoma. The basic demographics of this group and the 
Table III. Relationship of high CRM1 expression with serum LDH, ALP and other clinicopathological factors in patients with osteosarcomas.

\begin{tabular}{|c|c|c|c|c|}
\hline Characteristic & All cases & CRM1 normal (\%) & CRM1 increased (\%) & P-value \\
\hline Serum LDH $(n=57)$ & & & & 0.065 \\
\hline Normal & 44 & $24(54.5)$ & $20(45.5)$ & \\
\hline Increased & 13 & $4(30.8)$ & $9(69.2)$ & \\
\hline Serum ALP $(n=57)$ & & & & 0.002 \\
\hline Normal & 18 & $13(72.2)$ & $5(27.8)$ & \\
\hline Increased & 39 & $15(38.5)$ & $24(61.5)$ & \\
\hline Gender & & & & 0.06 \\
\hline Male & 34 & $20(58.8)$ & $14(41.2)$ & \\
\hline Female & 23 & $8(34.8)$ & $15(65.2 \%)$ & \\
\hline History of symptoms & & & & 0.22 \\
\hline$<70$ days & 25 & $14(56.0)$ & $11(44.0)$ & \\
\hline$\geq 70$ days & 32 & $14(43.8)$ & $18(56.2 \%)$ & \\
\hline Tumor size & & & & 0.014 \\
\hline$<$ one third & 31 & $15(48.4)$ & $16(51.6)$ & \\
\hline$\geq$ one third & 26 & $13(50.0)$ & $13(50.0)$ & \\
\hline Metastasis & & & & 0.84 \\
\hline $\mathrm{M}_{0}$ & 44 & $22(50.0)$ & $22(50.0)$ & \\
\hline $\mathrm{M}_{1}$ & 13 & $6(46.2)$ & $7(53.8)$ & \\
\hline Histological grade & & & & 0.003 \\
\hline G1 & 32 & $21(65.6)$ & $11(34.4)$ & \\
\hline G2 & 17 & $6(35.3)$ & $11(64.7)$ & \\
\hline G3 & 6 & $1(16.7)$ & $5(83.3)$ & \\
\hline G4 & 2 & 0 & 2 & \\
\hline Age (years) & & & & 0.32 \\
\hline$<12$ & 11 & $6(54.5)$ & $5(45.5)$ & \\
\hline$\geq 12$ & 46 & $22(47.8)$ & $24(52.2)$ & \\
\hline \multicolumn{5}{|l|}{ Necrosis rate } \\
\hline post chemotherapy & & & & 0.86 \\
\hline$<90 \%$ & 30 & $15(50.0)$ & $15(50.0)$ & \\
\hline$\geq 90 \%$ & 27 & $13(48.1)$ & $14(51.9)$ & \\
\hline
\end{tabular}

pathological characteristics are shown in Table I, respectively. The median age was 23.2 years (range 5-57). Most of patients were in the range 12-25 years. Twenty-seven (47.4) patients obtained limb salvage surgical treatment, 18 cases had a relapse and 22 died during the follow-up.

CRM1 protein expression in human osteosarcoma is increased compared to that in normal tissues. We determined expression of CRM1 protein in tumor tissues of 57 cases of osteosarcoma patients and in normal tissues of 5 cases, non-tumor patients, by Western blotting. As shown in Fig. 1, compared with the low CRM1 expression in normal tissues, the CRM1 expression in osteosarcoma tissues showed obviously increased levels. There were 29 patients with high CRM1 expression of the total 57 patients, and none of the 5 normal tissues expressed increased CRM1 (Table II). This significant difference of CRM1 expression in osteosarcomas and normal tissues $(\mathrm{P}=0.037)$ suggested that CRM1 might be a prognostic factor in osteosarcoma.

High CRM1 expression related with some clinicopathological factors in patients with osteosarcomas. We investigated the expression of CRM1 by Western blotting (Fig. 1) and analyzed the correlation between high expression of CRM1 and clinicopathological factors in patients with osteosarcomas, including serum ALP and LDH. Our data demonstrated that the increased expression of CRM1 was significantly associated with increased serum level of ALP $(\mathrm{P}=0.001)$ but did not associate with that of LDH $(\mathrm{P}=0.065)$. There was also a significant association 
A

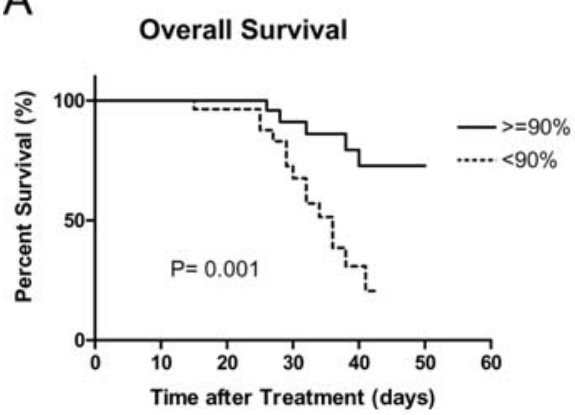

B

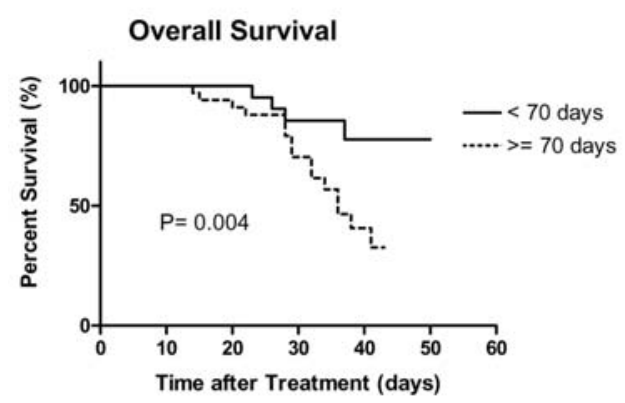

C

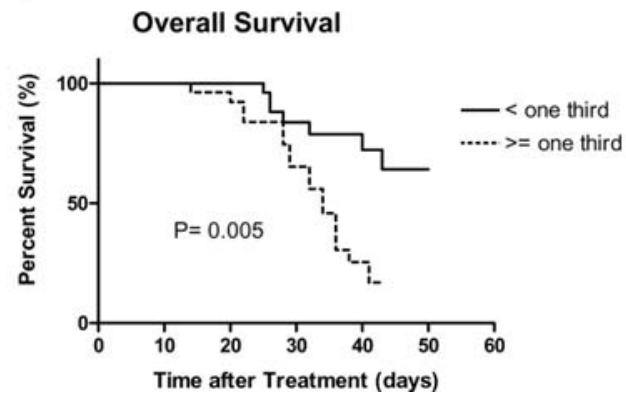

Progression-free Survival
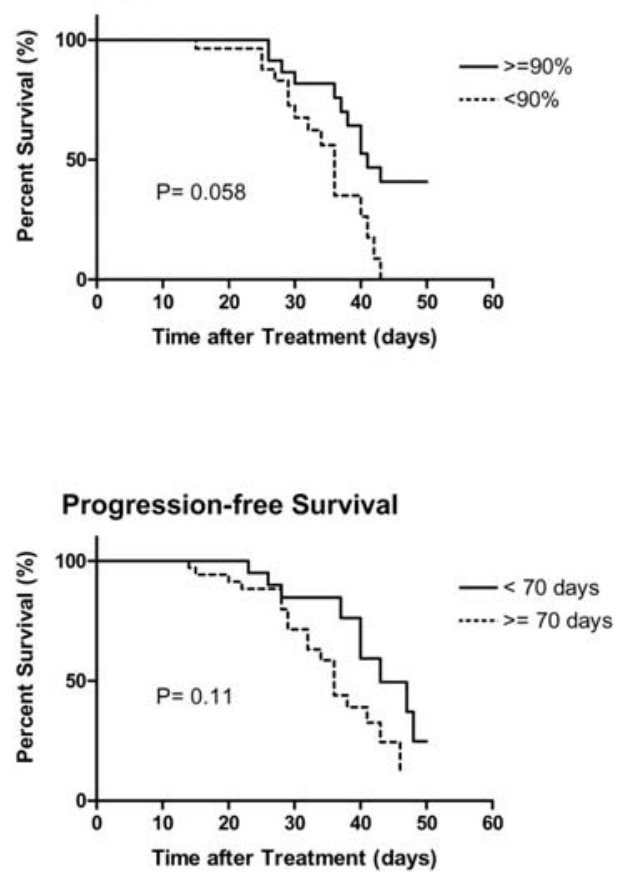

Progression-free Survival

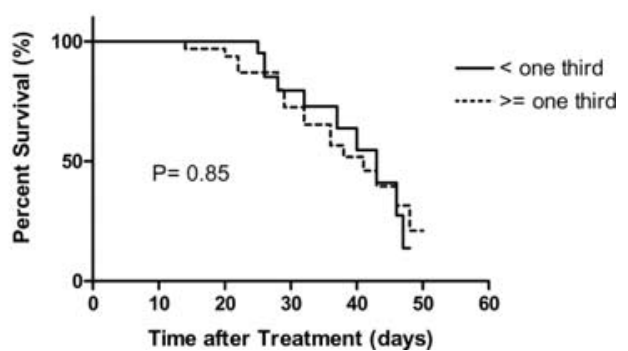

Figure 3. Kaplan-Meier survival analysis of overall survival and progression survival of (A) necrosis rate post-chemotherapy, (B) history of symptom and (C) tumor.

between CRM1 expression and tumor size $(\mathrm{P}=0.014)$ as well as histological grade $(\mathrm{P}=0.003)$, while expression of CRM1 was not correlated with gender, tumor size, metastasis or age (Table III).

High CRMI expression is a prognostic factor for overall and progression-free survival in univariate Kaplan-Meier analysis. In Kaplan-Meier survival analysis, high expression of CRM1 was a significant prognostic indicator for overall $(\mathrm{P}=0.008)$ as well as progression-free survival $(\mathrm{P}=0.016)$ (Fig. 2). In addition, the presence of metastases and histological grade were significant prognostic indicators for overall and progression-free survival (Fig. 2). Necrosis rate post-chemotherapy, history of symptoms and tumor size were significant prognostic indicators for overall survival but not for progression-free survival (Fig. 3).

Multivariate survival analysis. Results by multivariate survival analysis demonstrated that high CRM1 expression, increased serum ALP, the presence of metastasis, worse histological grade and $<90 \%$ tumor necrosis were significantly related to shorter survival (Table IV).

\section{Discussion}

Osteosarcoma is the most frequent malignant tumor of childhood, excluding hematopoietic malignancy (22). It usually occurs in patients between 10 and 25 years of age, which suggests an abnormality in the growing bone cells that leads to malignant disease. In addition, osteosarcoma is slightly more common in tall children and in males $(23,24)$. Most osteosarcoma arising are located in the metaphyseal area of the long bones, particularly, lower end of femur, the upper end of tibia and the upper end of the humerus. Various prognostic factors are tumor size, response to chemotherapy, post-chemotherapy tumor necrosis, and serum elevation of alkaline phosphatase levels. Metastases at diagnosis were present in $23 \%$ of our patients, which is higher than the 
Table IV. Multivariate survival analysis (Cox regression model) for overall survival of 57 patients with osteosarcomas.

\begin{tabular}{lll}
\hline Characteristic & RR $(95 \% \mathrm{CI})$ & P-value \\
\hline
\end{tabular}

\begin{tabular}{lcc}
\hline CRM1 expression & & \\
High & 1.00 & \\
Low & $2.83(1.27-5.39)$ & 0.006
\end{tabular}

Serum LDH $(\mathrm{n}=57)$

Normal

1.00

Increased

$2.39(0.85-6.72)$

0.05

Serum ALP $(n=57)$

Normal

1.00

Increased

$2.52(1.32-4.55)$

0.007

Gender

Male

Female

1.00

$2.62(0.85-6.72)$

0.098

History of symptoms

$<70$

1.00

$\geq 70$

$2.83(0.45-4.36)$

Tumor size

$<$ one third

1.00

$\geq$ one third

$2.45(1.22-5.19)$

0.06

Metastasis

$\mathrm{M}_{0}$

$\mathrm{M}_{1}$

Histological grade

G1-G2

G3-G4

$2.41(1.56-5.75)$

Age (years)

$<12$

$\geq 12$

$1.51(0.67-3.41)$

0.32

Necrosis rate

post Chemotherapy $<90$

$\geq 90$

$2.54(1.52-5.63)$

0.005

$\mathrm{RR}$, relative risk; CI, confidence interval.

frequency reported by other investigators (25-27). This clinical characteristic reflects the frequency of advanced disease at diagnosis among our patient population. We then documented the possible reasons for this characteristic. The significant correlation of the presence of metastases with the time from onset of symptoms to diagnosis, tumor size, or pathological grade has been demonstrated. It was reported that primary tumor spread was associated with shorter prediagnostic symptom duration and hypothesized that this could be related to a more aggressive biologic behavior (28). In our studies, the history of symptoms, the presence of metastases, pathological grades and tumor size were identified as the significant factors influencing outcome. Among them, the history of symptoms is an improvable clinical factor. By establishing a collaborated group of diagnosis and treatment of osteosarcoma in China, we can educate the potential patients and doctors to be alert to the symptoms of this disease and may therefore increase the rate of early diagnosis. Shortening the time from the set of symptoms to diagnosis may benefit the prognosis of the patients in China.

Several studies have demonstrated that CRM1 is important in nuclear-cytoplasmic transport and control of mitosis. Regarding the transport function, CRM1 is the main nuclear export receptor in humans (29-33). Mechanistic studies have demonstrated that some important molecules related to tumor biology depend on the CRM1 nuclear export pathway (34-37). It has also been demonstrated that CRM1 functions in complex with ras-related nuclear protein guaosine triphosphatase (RAN-GTPase) to control several processes during cellular mitosis. Therefore, CRM1 may associate with carcinogenesis.

In this study, we investigated the expression of the human CRM1 protein in osteosarcoma and in normal tissue. To our knowledge, this is the first study investigating expression of CRM1 in osteosarcoma and second study in cancer (19). The expression of CRM1 was higher in osteosarcomas compared with that in normal tissues. These tumors showed a significantly higher mitotic rate and were poorly differentiated. Patients with osteosarcomas showing increased CRM1 expression had a reduced progression-free and overall survival rate.

The cellular mechanisms responsible for the worst prognosis of tumors with an increased expression of CRM1 are still unknown. Our statistical analysis, suggests a link between overexpression of CRM1 and increased serum level of ALP. It is also supported by our analysis that there is an association between high CRM1 expression and worse pathological grade. Since ALP expression is not correlated with differentiation, it is possible that another CRM1 target is involved, which is important for cell differentiation. Additional studies will be required to analyze the molecules related to cell differentiation that are regulated by CRM1 in osteosarcoma.

It should be emphasized that the present study is a retrospective study with some limitations. In our study group, data on therapy as well as intraoperative residual tumor were retrospectively not available for all patients and could therefore not be included in the multivariate analysis. Additional large-scale prospective and retrospective studies are needed to investigate whether CRM1 expression is indeed of practical utility as a prognostic predictor.

Generally, when the determination of the immunoreactive pattern of CRM1 expression is combined with other clinicopathological factors, it may improve the prognostic evaluation of osteosarcoma patients. The CRM1 is a prognostic factor in human osteosarcoma and may contribute to identification of individuals who are at high risk for poor survival. 


\section{Acknowledgements}

This study was supported by Oriented Item of STCSM (064119637).

\section{References}

1. Kager L, Zoubek A, Pötschger U, Kastner U, Flege S, KempfBielack B, Branscheid D, Kotz R, Salzer-Kuntschik M, Winkelmann W, Jundt G, Kabisch H, Reichardt P, Jürgens H, Gadner H and Bielack SS: Primary metastatic osteosarcoma: presentation and outcome of patients treated on neoadjuvant cooperative osteosarcoma study group protocols. J Clin Oncol 21: 2011-2018, 2003.

2. Longhi A, Fabbri N, Donati D, Capanna R, Briccoli A, Biagini R, Bernini G, Ferrari S, Versari M and Bacci G: Neoadjuvant chemotherapy for patients with synchronous multifocal osteosarcoma: results in eleven cases. J Chemother 13: 324-330, 2001

3. Bacci G, Briccoli A, Rocca M, Ferrari S, Donati D, Longhi A, Bertoni F, Bacchini P, Giacomini S, Forni C, Manfrini M and Galletti S: Neoadjuvant chemotherapy for osteosarcoma of the extremities with metastases at presentation: recent experience at the Rizzoli Institute in 57 patients treated with cisplatin, doxorubicin, and a high dose of methotrexate and ifosfamide. Ann Oncol 14: 1126-1134, 2003.

4. Goorin AM, Harris MB, Bernstein M, Ferguson W, Devidas M, Siegal GP, Gebhardt MC, Schwartz CL, Link M and Grier HE: Phase II/III trial of etoposide and high-dose ifosfamide in newly diagnosed metastatic ostesarcoma: a Pediatric Oncology Group trial. J Clin Oncol 20: 426-433, 2002

5. Mialou V, Philip T, Kalifa C, Perol D, Gentet JC, Marec-Berard P, Pacquement H, Chastagner P, Defaschelles AS and Hartmann O: Metastatic osteosarcoma at diagnosis: prognostic factors and long-term outcome-the French Pediatric Experience. Cancer 104: 1100-1109, 2005.

6. Cormier JN and Pollock RE: Soft tissue sarcomas. CA Cancer J Clin 54: 94-109, 2004

7. Clark MA, Fisher C and Judson I: Soft-tissue sarcomas in adults. N Engl J Med 353: 701-711, 2005.

8. Fletcher CDM, Unni KK and Mertens F: World Health Organization Classification of Tumours. Pathology and Genetics of Tumours of Soft Tissue and Bone. IARC Press, Lyon, 2002.

9. Perbal B, Zuntini M, Zambelli D, Serra M, Sciandra M, Cantiani L, Lucarelli E, Picci P and Scotlandi K: Prognostic value of CCN3 in osteosarcoma. Clin Cancer Res 14: 701-709, 2008.

10. Kubo T, Piperdi S, Rosenblum J, Antonescu CR, Chen W, Kim HS, Huvos AG, Sowers R, Meyers PA, Healey JH and Gorlick R: Platelet-derived growth factor receptor as a prognostic marker and a therapeutic target for imatinib mesylate therapy in osteosarcoma. Cancer 112: 2119-2129, 2008.

11. Bacci G, Picci P, Ferrari S, Orlandi M, Ruggieri P, Casadei R, Ferraro A, Biagini R and Battistini A: Prognostic significance of serum alkaline phosphatase measurements in patients with osteosarcoma treated with adjuvant or neoadjuvant chemotherapy. Cancer 71: 1224-1230, 1993

12. Bacci G, Longhi A, Ferrari S, Briccoli A, Donati D, De Paolis M and Versari M: Prognostic significance of serum lactate dehydrogenase in osteosarcoma of the extremity: experience at Rizzoli on 1421 patients treated over the last 30 years. Tumori 90: 478-484, 2004.

13. Han X, Saito H, Miki Y and Nakanishi A: A CRM1-mediated nuclear export signal governs cytoplasmic localization of BRCA2 and is essential for centrosomal localization of BRCA2 Oncogene 27: 2969-2977, 2008.

14. Sanchez V, Mahr JA, Orazio NI and Spector DH: Nuclear export of the human cytomegalovirus tegument protein pp65 requires cyclin-dependent kinase activity and the Crm1 exporter. J Virol 81: 11730-11736, 2007.

15. Hutten S and Kehlenbach RH: Nup214 is required for CRM1dependent nuclear protein export in vivo. Mol Cell Biol 26: 6772-6785, 2006.

16. Panasyuk G, Nemazanyy I, Zhyvoloup A, Bretner M, Litchfield DW, Filonenko V and Gout IT: Nuclear export of S6K1 II is regulated by protein kinase CK2 phosphorylation at Ser-17. J Biol Chem 281: 31188-31201, 2006.
17. Shinmura K, Tarapore P, Tokuyama Y, George KR and Fukasawa K: Characterization of centrosomal association of nucleophosmin/B23 linked to Crm1 activity. FEBS Lett 579: 6621-6634, 2005

18. Poon IK, Oro C, Dias MM, Zhang J and Jans DA: Apoptin nuclear accumulation is modulated by a CRM1-recognized nuclear export signal that is active in normal but not in tumor cells. Cancer Res 65: 7059-7064, 2005.

19. Noske A, Weichert W, Niesporek S, Röske A, Buckendahl AC, Koch I, Sehouli J, Dietel M and Denkert C: Expression of the nuclear export protein chromosomal region maintenance/ exportin 1/Xpo1 is a prognostic factor in human ovarian cancer. Cancer 112: 1733-1743, 2008.

20. Ranganathan A, Yazicioglu MN, and Cobb MH: The nuclear localization of ERK2 occurs by mechanisms both independent of and dependent on energy. J Biol Chem 281: 15645-15652, 2006.

21. Shen Z, Wen XF, Lan F, Shen ZZ and Shao ZM: The tumor suppressor gene LKB1 is associated with prognosis in human breast carcinoma. Clin Cancer Res 8: 2085-2090, 2002.

22. Birch JM, Alston RD, Quinn M and Kelsey AM: Incidence of malignant disease by morphological type, in young persons aged 12-24 years in England, 1979-1997. Eur J Cancer 39: 2622-2631, 2003

23. Cotterill SJ, Wright CM, Pearce MS and Craft AW: UKCCSG/ MRC bone tumour working group: Stature of young people with malignant bone tumors. Pediatr Blood Cancer 42: 59-63, 2004.

24. Grimer RJ: Surgical options for children with osteosarcoma. Lancet Oncol 6: 85-92, 2005.

25. Bielack SS, Kempf-Bielack B and Delling G: Prognostic factors in high-grade osteosarcoma of the extremities or trunk: An analysis of 1,702 patients treated on neoadjuvant cooperative osteosarcoma study group protocols. J Clin Oncol 20: 776-790, 2002.

26. Meyers P, Schwartz C, Krailo M, et al: Osteosarcoma: A randomized, prospective trial of the addition of ifosfamide and/or muramyl tripeptide to cisplatin, doxorubicin, and highdose methotrexate. J Clin Oncol 23: 2004-2011, 2005.

27. Meyers PA, Heller G, Healey JH, Huvos A, Applewhite A, Sun M and LaQuaglia M: Osteogenic sarcoma with clinically detectable metastasis at initial presentation. J Clin Oncol 11: 449-453, 1993.

28. Bacci G, Ferrari S, Longhi A, Forni C, Zavatta M, Versari M and Smith K: High grade osteosarcoma of the extremity: Differences between localized and metastatic tumors at presentation. J Pediatr Hematol Oncol 24: 27-30, 2002.

29. Kudo N, Khochbin S, Nishi K, Kitano K, Yanagida M, Yoshida M and Horinouchi S: Molecular cloning and cell-cycle dependent expression of mammalian CRM1, a protein involved in nuclear export of proteins. J Biol Chem 272: 29742-29751, 1997.

30. Stade K, Ford CS, Guthrie C and Weis K: Exportin 1 (CRM1p) is an essential nuclear export factor. Cell 90: 1041-1050, 1997.

31. Yoshida M and Horinouchi S: Trichostatin and leptomycininhibition of histone deacetylation and signal-dependent nuclear export. Ann NY Acad Sci 886: 23-36, 1999

32. Gallouzi IE and Steitz JA: Delineation of mRNA export pathways by the use of cell-permeable peptides. Science 294: 1895-1901, 2001

33. Jang BC, Munoz-Najar U, Paik JH, Claffey K, Yoshida M and Hla T: Leptomycin B, an inhibitor of the nuclear export receptor CRM1, inhibits COX-2 expression. J Biol Chem 278: 2773-2776, 2003.

34. Stommel JM, Marchenko ND, Jimenez GS, Moll UM, Hope TJ and Wahl GM: A leucine-rich nuclear export signal in the p53 tetramerization domain: regulation of subcellular localization and p53 activity by NES masking. EMBO J 18: 1660-1672, 1999.

35. Harrison BC, Roberts CR, Hood DB, Sweeney M, Gould JM, Bush EW and McKinsey TA: The CRM1 nuclear export receptor controls pathological cardiac gene expression. Mol Cell Biol 24: 10636-10649, 2004.

36. Saji M, Vasko V, Kada F, Allbritton EH, Burman KD and Ringel MD: Akt1 contains a functional leucine-rich nuclear export sequence. Biochem Biophys Res Commun 332: 167-173, 2005.

37. Lo HW, Seyed MA, Wu Y, Bartholomeusz G, Hsu SC and Hung MC: Nuclear-cytoplasmic transport of EGFR involves receptor endocytosis, importin b1 and CRM1. J Cell Biochem 98: 1570-1583, 2006. 